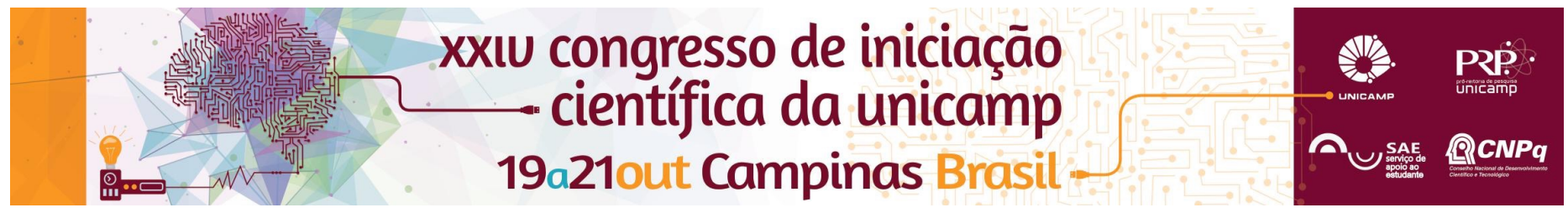

\title{
The Use of Metadata in the Development of Interactive Audiovisual Narratives Franco Araujo Simões*
}

\begin{abstract}
In her book, "Hamlet in the Holodeck", Janet Murray (2003) describes the capacity that new media and the digital environment have to develop their own forms of expressivity, and the lack of practical efforts invested in the creation of products that explore them. This is the subject of research of many other theorists such as Espen Aarseth (1997) and Lev Manovich, who released the book, "The Language of New Media" (MANOVICH, 2001), and the project, "Soft Cinema" (KRATKY; MANOVICH, 2005), in which he implements the use of database narrative and algorithmic editing. Inspired by such projects and by theoretical studies in New Media and Digital Narratives, this research proposes a new theoretical and practical approach to interactive audiovisual narratives, joining the Procedimental property of the digital medium (by using the concepts of database narrative and algorithmic editing) and its Participative property (by using an interactive interface between the work and its user), to develop a model of an interactive audiovisual product, whose core aspect will be the use of metadata as an editing tool.
\end{abstract}

\section{Key words:}

Algorithm editing, Audiovisual, Database Narrative

\section{Introduction}

The research of theorists of different areas of study - especially literature, linguistics, cinema and computer sciences - shows that, even though the convergence of media is already in course (today we can verify the translation of different media to the digital environment, such as photographs, ebooks, and movies and series offered online), it is necessary to commit to the expansion of digitally native storytelling strategies, that seek in the digital environment's essential characteristics the tools for developing its own language.

It is with that in mind that this research focuses on Databases, Algorithms and Interfaces, exploring their relationship with preexisting narratives (the study sticks to audiovisual platforms) and determining their creative potential.

In practical terms, the research provided the development of an algorithm editing software, that creates videos in real time based in a database of short videos, its metadata and the user's participation. This software allowed a deeper understanding of specific subjects around the central theme of the research, such as: Database Narratives; Interfaces' communicative importance; System - User interaction; and the relevance of database as a central element to new media language.

\section{Results and Discussion}

The development of the software itself came from a wide theoretical research on Database Narrative, Algorithms' logics, participative narratives, interactive systems and Human-Computer Interfaces. The software confirmed some of the research's initial ideas (e.g. the importance of interface not only in the establishment of the interaction with the user, but in the creation of the message itself) and proposed further considerations regarding to the interpretation of the narratives created by the software (in a first moment, database and narrative are contradictory concepts, since the latter is defined by linearity and the former is defined by the lack of it) and to the different concepts of interactivity - the theoretical research on interactive systems pointed to the existence of a wide variety of definitions and levels of complexity of interactivity: how can one work with the complexity of the interaction between the user and the software's editing mechanism in a way to create an understandable system, that is not only reactive, but truly interactive?
In the moment of the subscription, the research is still ongoing, therefore the discussions are going to be taken further and the software will be updated and refined. The next stage of the research involves the creation of different interfaces for the software, exploring the ways in which it can provide the interaction between the user, the editing mechanism and the output.

\section{Conclusions}

It is possible to use the digital medium's intrinsic characteristics to create new kinds of narratives with unique styles. It is even possible to bring the spectator to a more active position in the consumption of the art piece - making her a user, and allowing her to actively participate in the final result.

The research shows the different possibilities of interactions between the user, the creative platform and the final result, exploring not only the new creative potential of the medium, but also the new interpretative exigencies brought by the establishing new media language.

\section{Acknowledgement}

I would like to thank my supervisor, José Armando Valente, for the constant support, and my brother, Vitor Araujo Simões, for helping me in moments of technical difficulties. Sponsor Institution: FAPESP

AARSETH, Espen J. Cybertext: perspectives on ergodic literature. Baltimore, Md.; London: Johns Hopkins University Press, 1997. 203 p.

KRATKY, Andreas (Coaut. de); MANOVICH, Lev. Soft cinema: navigating the database. Cambridge, MA: The MIT, c2005. 1 v. (não paginado)

MANOVICH, Lev. The language of new media. Cambridge, MA: MIT, c2001. Xxxix, $354 \mathrm{p}$

MURRAY, Janet H. Hamlet no Holodeck: o futuro da narrativa no ciberespaço. São Paulo, SP: Editora UNESP: Itaú Cultural, 2003. 282 p. 